\title{
Evaluation, Source of Educational Growth and Regional Comparison of Higher Education Productivity in China*
}

\author{
Qizhong Deng ${ }^{1}$ \\ Hunan University of Science and Technology \\ Zheng $\mathrm{Ye}^{2}$ \\ Hunan University of Science and Technology
}

\begin{abstract}
This paper analyzes the dynamic evolution and regional disparity of Chinese higher education productivity in 29 provinces by adopting SBM directional distance function and Malmquist productivity index. The data set has been utilized for the period of 2007-2015 according to data availability. Later, the source of educational growth is explored though index decomposition. Results reveal that: Chinese higher education productivity is on the rise and its growth rate varies during different periods. The higher education productivity during the "Eleventh Five-year Plan" has increased, with an average annual growth rate of 5\%. The growth rate of higher education productivity during "The twelfth Five-year Plan" was significantly slower as compared to "The Eleventh Five-year Plan" with an average annual growth rate of $1 \%$. Moreover, Chinese higher education has an average annual growth rate of $2 \%$ in the total factor productivity. Technological progress and technical efficiency have an average annual rate of $1 \%$, which indicates that higher education productivity growth is the result of both technological progress and technical efficiency. Taking the regional difference in consideration, the development of Chinese higher education productivity seems unbalanced. There were significant interurban differences and spatial differences in higher education productivity. The higher education productivity growth rate of eastern region was faster as compared to northeast, central and western areas. The annual average productivity index of nine regions has improved, among which higher education productivity growth rate of Zhejiang province is the largest. However, annual average productivity index of 17 regions is observed declining, and the biggest drop is in Inner Mongolia region.
\end{abstract}

\section{Keywords}

Higher Education • Productivity • Source of Growth • Malmquist Index

\footnotetext{
* The authors would like to thank the referee for his helpful advice and comments. This is a project supported by Postdoctoral Science Foundation of China (2016M592425) and Scientific Research Fund of Hunan Provincial Education Department(16A079).

${ }^{1}$ Correspondence to: School of Business, Hunan University of Science and Technology, Xiangtan 411201, China; College of Business Administration, Hunan University, Changsha 410012, China; Email: dqzdesertsea@163.com

${ }^{2}$ School of Business, Hunan University of Science and Technology, Xiangtan 411201, China. Email: 1255993925@qq.com
} 
With the continuous emergence of regional characteristics of higher education in China, its coordinated development has attracted society attention. Since the popularization of higher education in 1999, higher education development in China has obtained some achievements, however, problems such as insufficient investment and unbalanced regional development have been difficult to address efficiently. Realizing the rationalization and standardization of higher education resources and improving the efficiency of higher education in various regions has always been an important way to realize the coordinated development of higher education in China. Therefore, depth of research on regional higher education productivity, not only can effectively give full consideration to the advantages of universities in regional development, promote balanced allocation of higher education resources in different region and promote development of universities and regions, but also has profound theoretical value and practical significance to improve higher education evaluation system.

Foreign scholars pay attention to higher education productivity. The concept, characteristics and influencing factors of higher education productivity were studied from different angles, and they were further extended (Fraser et al., 1987; Levin, 1991; Monk, 1992; Odden, 1995). The non-parametric efficiency evaluation method represented by data envelopment analysis (DEA) has been widely used by foreign scholars in the evaluation of higher education efficiency. For example, Sarrico et al., (1997) ranked the performance and contribution of various universities by using DEA model. The Malmquist index has been carried out an empirical study on input-output panel data of universities. Domestic scholars also considered the importance of research on the higher education productivity. In the evaluation of education efficiency, efficiency evaluation method represented by data envelopment analysis (DEA) has been widely accepted and used. Li Qian (2015) has utilized the super-efficiency DEA model to evaluate the input-output efficiency of higher education in China before and after expansion. Most scholars have used Malmquist index to measure higher education productivity in China. The research shows that: Chinese higher education productivity overall is on rise (Han \& $\mathrm{Li}, 2010)$ and the main source of growth is technological progress (Zhong \& Jiang, 2017) however, there were the signal of greater instability and unbalanced characteristics of regional development (Pan \& Zhou, 2007).

The existing research has made a positive influence on the higher education productivity in China and some useful conclusions can be drawn, however, there are still some shortcomings; First, the input-output indicators of higher education were not comprehensive. At one side, most of the scholars regarded the number of teachers and education funds as input indicators but overlooked the input of scientific research. On the other hand, output indicators were mainly measured by the number of junior college students and undergraduates but output effect of post-undergraduates is not taken into consideration. Second, some articles measured higher education productivity in one year or several years, but ignored its dynamic change. Owing the deficiencies in previous literature, this paper uses super-efficiency of SBM directional distance function and Malmquist index to measure higher education productivity of 29 provinces in China from 2007 to 2015 and analyzes its evolution characteristics and spatial differences. Finally, paper also explores the source of its growth through index decomposition method.

The rest of the paper is structured as: Section 2 is for model, method and data. Section 3 is for results and discussion and section 4 concludes the paper with policy suggestions. 


\section{Model, Method and Data}

\section{Super-Efficient SBM Directional Distance Function}

The SBM model is a non-radial DEA model based on the calculation efficiency of slack variables proposed by Kaoru Tone (Tone, 2001). On the basis of general DEA model, it takes slack variables into the consideration when calculating efficiency of decision unit, which makes up defect of general DEA model. However, efficiency of the effective decision unit cannot be compared and sorted by using SBM model. To make up this defect, Kaoru Tone proposed super-efficient SBM model based on SBM model. The super-efficient SBM model is expressed as follows;

$$
\begin{aligned}
& \delta^{*}=\min \delta=\frac{\frac{1}{m} \sum_{i=1}^{m} \frac{x_{i}}{x_{i 0}}}{\frac{1}{s} \sum_{i=1}^{m} \frac{y_{r}}{x_{r 0}}} \\
& \text { s. t. }\left\{\begin{array}{l}
\bar{x} \geq \sum_{j=1, \neq 0}^{n} \lambda x_{i} \quad \bar{y} \leq \sum_{j=1, \neq 0}^{n} \lambda y_{i} \quad \sum_{j=1, \neq 0}^{n} \lambda_{i}=1 \\
\bar{x} \geq x_{0}, y \leq y_{0}, \bar{y} \geq 0, \lambda \geq 0
\end{array}\right.
\end{aligned}
$$

Among them, $\delta^{*}$ is called efficiency value, $m$ and $s$ mean the number of input and output variables respectively, $s_{i}^{-}$and $s_{i}^{+}$stand for slack variables of input and output respectively.

\section{Malmquist Index Model}

To measure and decompose higher education productivity in China, dynamic analysis on the Malmquist index of productivity based on the distance function is required and the Malmquist index of the period $t$ and period $\mathrm{t}+1$ can be expressed as:

$$
\begin{gathered}
M_{0}^{t}\left(Y_{t+1}, X_{t+1}, Y_{t}, X_{t}\right)=\left[\frac{d_{0}^{t}\left(Y_{t+1}, X_{t+1}\right)}{d_{0}^{t}\left(Y_{t}, X_{t}\right)}\right] \\
M_{0}^{t+1}\left(Y_{t+1}, X_{t+1}, Y_{t}, X_{t}\right)=\left[\frac{d_{0}^{t+1}\left(Y_{t+1}, X_{t+1}\right)}{d_{0}^{t+1}\left(Y_{t}, X_{t}\right)}\right]
\end{gathered}
$$

To avoid the arbitrariness of the benchmark, paper uses geometric mean as the Malmquist index for productivity changes from time $t$ to time $t+1$.

$$
T F P=M_{0}^{t+1, t}\left(Y_{t+1}, X_{t+1}, Y_{t}, X_{t}\right)=\left[\frac{d_{0}^{t}\left(Y_{t+1}, X_{t+1}\right)}{d_{0}^{t}\left(Y_{t}, X_{t}\right)} \bullet \frac{d_{0}^{t+1}\left(Y_{t+1}, X_{t+1}\right)}{d_{0}^{t+1}\left(Y_{t}, X_{t}\right)}\right]^{\frac{1}{2}}
$$

Assuming that the scale compensation is constant, Malmquist index of the period $t$ and period $t+1$ is decomposed into the change of relative Technical Efficiency and Technological Progress, the above formula can be changed to: 


$$
T F P=M_{0}^{t+1, t}\left(Y_{t+1}, X_{t+1}, Y_{t}, X_{t}\right)=\frac{d_{0}^{t+1}\left(Y_{t+1}, X_{t+1}\right)}{d_{0}^{t}\left(Y_{t}, X_{t}\right)}\left[\frac{d_{0}^{t}\left(Y_{t+1}, X_{t+1}\right)}{d_{0}^{t+1}\left(Y_{t+1}, X_{t+1}\right)} \cdot \frac{d_{0}^{t}\left(Y_{t}, X_{t}\right)}{d_{0}^{t+1}\left(Y_{t}, X_{t}\right)}\right]^{\frac{1}{2}}
$$

In the above equation $\frac{d_{0}^{t+1}\left(Y_{t+1}, X_{t+1}\right)}{d_{0}^{t}\left(Y_{t}, X_{t}\right)}$ (TEC) is the change of relative technical efficiency, indicating the degree of technological change of higher education productivity during the period $t$ and period $t+1$, the second term (TC) is the change of technological progress, indicating the degree of technological change of higher education productivity in two periods.

\section{Index System and Data}

The present higher education investment indexes can be classified into three categories: human resources, material resources and financial resources. The output indexes can be divided into two aspects: talent cultivation and technological innovation. In view of the fact that full-time teachers, administrators, staff members and logistics personnel make the biggest contribution to the output of colleges and universities, the input of human resources in this paper is represented by the number of full-time teachers and the number of administrative staffs. Material resources is represented by public libraries and fixed assets. To accurately reflect the most closely related funds input of universities and teaching and research activities, this paper takes scientific research funds and per-student educational expenditure as material resources inputs. Teaching output directly reflected in the number of college students. Considering that the different training level of students make different contributions to the output of higher education, the number of master students in the school and the number of doctoral students in the school are calculated according to the weights of 1:1.5:2. Because it's difficult to unify the weights of various achievements in scientific research and academic papers and patents authorized are recognized by all colleges, this paper takes the publication of academic papers and patent authorization as technological innovation outputs. This paper uses panel data of 29 provinces from 2007-2015 to analyze dynamic evolution and regional disparity of Chinese higher education productivity. To eliminate the sharp fluctuation in data, Tibet and Xinjiang are not included in the statistical category. The data are from China statistical yearbook, China education statistical yearbook, China education fund statistics yearbook, China social statistics yearbook, Compilation of scientific and technological statistics of Chinese higher school.

\section{Empirical Results and Analysis}

\section{Development Status of Higher Education Productivity in China}

Figure 1 shows China's higher education average productivity index and its decomposition from 2007 to 2015. First, higher education productivity index in China (from 2007 to 2015) is still with the upward trend despite a large fluctuation, its maximum value is $24 \%$ (in 2008), and the lowest value is -7\% (in 2009). Further, analyzing technical efficiency and technological progress, it is found that the average technical efficiency of higher education is higher than the average technological progress and the trend of average index of 
technological progress is basically same as the trend of productivity change. It indicates that the technical efficiency can improve higher education development. Second, trend of higher education productivity in China can be divided into two periods: first period is from 2007 to 2010 (11th Five-Year Plan). During this period, higher education productivity fluctuation was relatively large and the index of higher education productivity rise sharply from 2007 to 2008. It was mainly due to the high enrollment expansion of colleges before 2006 makes higher contribution to higher education output. However, index fell sharply in 2008-2009, from positive to negative growth. Perhaps due to the nation plans that slower down the development of higher education and reduces recruitment of students and investment on higher education, while paying more attention to improve school-running level at this stage. However, this plan does not work well for the development of higher education. The second period is $2010-2015$ ( $12^{\text {th }}$ Five-Year Plan). In this stage, index of higher education productivity was stable and the trend of technological progress index was basically same as the trend of productivity change, both showed positive growth, which indicates that China's higher education developed well during this period. It can be reasoned that the year of 2008 was the last year of the last batch of " 211 project" where universities were selected. After that, higher education enrollment expansion was over and some adjustment was made to stabilize the development status of higher education productivity. The index fluctuation around 1 and lower than the previous period reveals the low-efficiency growth. It requires measures to improve higher education development.

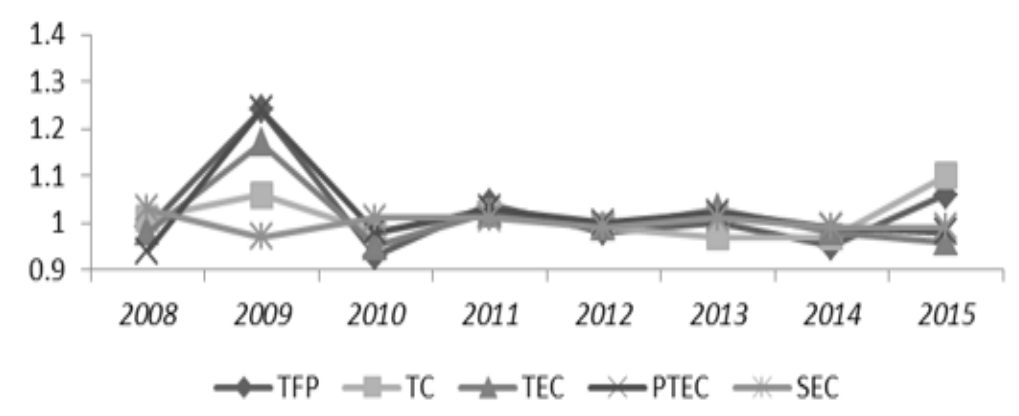

Figure 1. China'S Higher education average productivity index and its decomposition from 2007 To 2015

\section{Growth Source of Higher Education Development}

Table 1 depicts growth source of higher education development in China. It shows the average annual growth rate of higher education productivity from 2007 to 2015 was $2 \%, 1 \%$ in average annual technological progress and technical efficiency, which footprints that higher education productivity growth was the outcome of both technological progress and technical efficiency. The growth sources of higher education productivity vary from period to period. In " $11^{\text {th }}$ Five-Year Plan", higher education average annual growth rate was $5 \%$ in productivity, which is the result of technological progress and technical efficiency. Whereas, $2 \%$ in average annual technological progress and 3\% in technical efficiency. By decomposing technical efficiency, we can find that its rising caused by an average annual growth rate of $6 \%$ is in pure technical efficiency which indicates before 2006, with development of enrollment expansion of higher schools, higher education investment in 
capital and manpower increase rapidly. There is a time lag between higher education input and output, so "Project 211" phase three and "project 985" phase two, phase three were constructed in the field of higher education and intension development pattern was put forward, technological progress and technical efficiency are higher in the late " $11^{\text {th }}$ Five-Year Plan". It is worth mention that the college enrollment expansion and merger of this period did not make scale efficiency increase a lot.

Table 1

The Mean and Composition of Malmquist Index in Universities from 2007 to 2015

\begin{tabular}{|c|c|c|c|c|c|}
\hline Year/Period & TFP & TC & TEC & PTEC & SEC \\
\hline $2007-2008$ & 0.99 & 1.01 & 0.98 & 0.94 & 1.03 \\
\hline 2008-2009 & 1.24 & 1.06 & 1.17 & 1.24 & 0.97 \\
\hline $2009-2010$ & 0.93 & 0.98 & 0.95 & 0.98 & 1.01 \\
\hline " $11^{\text {th }}$ Five-Year Plan" & 1.05 & 1.02 & 1.03 & 1.06 & 1.00 \\
\hline 2010-2011 & 1.04 & 1.02 & 1.02 & 1.03 & 1.01 \\
\hline 2011-2012 & 0.98 & 0.99 & 0.99 & 1.00 & 0.99 \\
\hline $2012-2013$ & 1.00 & 0.97 & 1.03 & 1.02 & 1.01 \\
\hline 2013-2014 & 0.95 & 0.97 & 0.98 & 0.99 & 0.99 \\
\hline 2014-2015 & 1.06 & 1.10 & 0.96 & 0.98 & 0.99 \\
\hline "12 $2^{\text {th }}$ Five-Year Plan" & 1.01 & 1.01 & 1.00 & 1.00 & 1.00 \\
\hline Mean & 1.02 & 1.01 & 1.01 & 1.02 & 1.00 \\
\hline
\end{tabular}

Note. "TFP" stands for total factor productivity; "TC" stands for technological progress; "TEC" stands for technical efficiency; "PTEC" stands for pure technical efficiency; "SEC" stands for scale efficiency.

During "12th Five-Year Plan", average annual growth rate of higher education productivity was $1 \%$ that was lower than that of "11th Five-Year Plan" period. Among them, higher education has an average annual growth rate of $1 \%$ in technological progress, technical efficiency was unchanged and higher education productivity growth rely merely on technological progress. It indicates the university enrollment expansion until 2006. Further, it also may reveal that it seems difficult to guarantee higher education quality due to the expansion of colleges and universities. Therefore, it can suggest that we should pay more attention in improving higher education and it was tried since 2006 that lead to the higher education not only realized the rapid growth of the various inputs, and achieved the growth of higher education productivity during "11th Five-Year Plan" period. However, although its productivity was growing, its average annual growth rate was only $1 \%$, and was lower than the previous period that suggests the low-efficiency growth.

\section{Space Difference of Higher Education Productivity.}

Table 2 shows space difference of higher education productivity. Results reveal significant difference of higher education productivity among four regions. Among them, east region has the highest growth rate of $4 \%$, which is mainly due to technological progress. The productivity index of central region was 0.98 ; indicating higher education productivity of central region fell by $2 \%$ from 2007 to 2015 , mainly due to the decline in technological progress. The higher education productivity of the west region and northeast region fell $4 \%$ and $1 \%$ respectively, mainly caused by the decline of technological progress as well as technical efficiency. The differences in technical efficiency of four regions were small. The average technical efficiency fell by $1 \%$, which means that the effect on productivity caused by technical efficiency tends to be negative. The mean value of four regional technological progresses was 1.00 , which shows that technological progress is the main source of productivity growth. 
First, in terms of the differences from provinces and cities, according to the result of average productivity, average annual productivity index of nine provinces in China has been improved to some extent. The rise of Zhejiang province is the largest with average annual growth of $12 \%$, Tianjin, Jiangxi and Henan province's average annual productivity index remain same, but productivity index of 17 provinces and cities declined, in which the biggest drop down was recorded in Inner Mongolia autonomous region with fell by an annual rate of $13 \%$. Second, talking about the average technical efficiency index, 11 provinces and cities has shown rise in technical efficiency to some extent, while 14 provinces and cities had fallen. Fujian has the biggest growth rate of 5\%, while the highest drop down was recorded in Shanghai where average drop down was $10 \%$. It reflects that the higher education resource allocation ability, resource use efficiency and management level need to be improved in Shanghai. Third, in terms of average technological progress index, average technological progress index of 10 provinces and cities exceed 1 where the fastest growth was in Zhejiang province, reached 20\%, while average technological progress index of 13 provinces and cities has declined in different degrees, among them, the biggest drop was in Inner Mongolia autonomous region where average drop down was recorded $14 \%$. It indicates that Inner Mongolia autonomous region should strengthen cooperation with other provinces and cities to get the benefits of advance technology and improve level of management technology.

Table 2

Regional Higher Education Productivity Index and its Decomposition from 2007 to 2015

\begin{tabular}{l|ccccc|l|ccccc}
\hline Region & MI & TC & TEC & PTEC & SEC & Region & MI & TC & TEC & PTEC & SEC \\
\hline Beijing & 1.04 & 1.14 & 0.91 & 1.02 & 0.89 & Neimenggu & 0.87 & 0.86 & 1.02 & 0.96 & 1.06 \\
Shanghai & 1.05 & 1.17 & 0.90 & 0.93 & 0.96 & Guangxi & 0.93 & 0.95 & 0.98 & 0.97 & 1.01 \\
Zhejiang & 1.12 & 1.20 & 0.93 & 1.01 & 0.92 & Chongqing & 0.97 & 0.99 & 0.98 & 1.00 & 0.98 \\
Guangdong & 1.03 & 1.02 & 1.01 & 1.04 & 0.98 & Sichuan & 0.97 & 1.00 & 0.98 & 1.00 & 0.98 \\
Hainan & 0.98 & 0.96 & 1.02 & 1.02 & 1.00 & Guizhou & 0.93 & 0.95 & 0.98 & 0.96 & 1.02 \\
Tianjin & 1.00 & 1.00 & 1.00 & 1.00 & 1.00 & Yunnan & 1.06 & 1.04 & 1.02 & 1.01 & 1.01 \\
Hebei & 0.96 & 1.02 & 0.94 & 0.94 & 1.01 & Shanxi & 0.98 & 1.00 & 0.99 & 0.99 & 1.00 \\
Jiangsu & 1.08 & 1.15 & 0.94 & 1.04 & 0.91 & Gansu & 0.96 & 0.97 & 1.00 & 1.04 & 0.96 \\
Fujian & 1.09 & 1.04 & 1.05 & 1.02 & 1.03 & Ningxia & 0.96 & 0.96 & 1.00 & 0.97 & 1.02 \\
Shandong & 1.02 & 1.01 & 1.01 & 1.00 & 1.01 & Qinghai & 0.93 & 0.92 & 1.01 & 1.04 & 0.97 \\
The east & 1.04 & 1.07 & 0.97 & 1.00 & 0.97 & The west & 0.96 & 0.96 & 1.00 & 0.99 & 1.00 \\
Shanxi & 0.94 & 0.95 & 0.99 & 1.00 & 0.98 & Liaoning & 0.99 & 1.00 & 0.99 & 1.01 & 0.99 \\
Anhui & 1.02 & 1.00 & 1.02 & 1.01 & 1.01 & Jilin & 0.99 & 0.95 & 1.04 & 1.04 & 1.00 \\
Jiangxi & 1.00 & 0.98 & 1.03 & 1.00 & 1.03 & Heilongjiang & 0.98 & 1.03 & 0.95 & 0.96 & 0.99 \\
Henan & 1.00 & 0.99 & 1.01 & 1.01 & 1.01 & Northeast & 0.99 & 0.99 & 0.99 & 1.00 & 0.99 \\
Hubei & 0.99 & 1.00 & 0.99 & 0.99 & 1.00 & & & & & & \\
Hunan & 0.96 & 0.96 & 1.00 & 1.00 & 1.00 & & & & & & \\
The central & 0.98 & 0.98 & 1.01 & 1.00 & 1.01 & & & & &
\end{tabular}

Further, comparative analysis reveals that 9 provinces and cities' productivity index have improved caused by technical efficiency, besides Anhui. Productivity index of other provinces and cities ascended mostly rely on technological progress. Among them, index of technological progress and technical efficiency showed upward trend in Guangdong, Fujian, Shandong and Yunnan province. Besides Fujian province where technical efficiency made higher contribution to productivity growth, technological progress made more contribution to productivity growth in other provinces and cities. There were 17 provinces and cities where productivity index has declined and productivity index has declined mainly due to technological progress in Hainan, Inner Mongolia, Qinghai and Jilin. The technological progress of Hebei and Heilongiiang provinces has improved; however, productivity index has decreased. It can be due to the reduction of technical efficiency. The 
productivity index has declined in other provinces and cities. It may be the result of the reduction of technological progress and technical efficiency. Above analysis shows the higher education productivity growth and its source of growth are different, which means that regional cooperation, reasonable configuration and structure optimization of higher education resources require improvement.

\section{Conclusion}

This paper measured and evaluated China's higher education productivity from 2007 to 2015 by adopting super-efficiency SBM directional distance function and Malmquist index, and has revealed its characteristics from space-time evolution and regional prospective, provinces and cities' differences, and the main factors of the spatial difference of higher education productivity are further discussed. The following conclusions are drawn from the paper. First, overall, China's higher education productivity is on the rise and technological progress is the main source of its growth. According to the time series evolution, higher education productivity of $11^{\text {th }}$ Five-Year Plan was obvious in the stage of growth, while higher education productivity growth of the " $12^{\text {th }}$ Five-Year Plan" was fluctuated and was found slower than that of previous period. In the terms of the source of productivity growth, higher education productivity growth of the $11^{\text {th }}$ Five-Year Plan was the outcome of the increase of technical efficiency and technological progress. The growth of higher education productivity of the " $12^{\text {th }}$ Five-Year Plan" period has been slowed down. The higher education productivity has an average annual growth rate of $1 \%$ in technological progress and technical efficiency was unchanged, which indicate that the increase of technological progress was the main source of higher education productivity growth during the " $12^{\text {th }}$ Five-Year Plan" period.

Second, higher education productivity growth has differences in different regions. The highest productivity index was in the east region and its development was relative effective while average annual productivity index has shown negative growth in central, western and northeast region. Regional higher education unbalanced development pattern was found obvious. The annual average productivity index of 9 regions has improved, among which higher education productivity growth rate of Zhejiang province was the largest. However, annual average productivity index of 17 regions was observed declining, and the biggest drop was in Inner Mongolia region.

\section{References}

Fraser, B. J., Walberg, H. J., Welch, W. W., \& Hattie, J. A. (1987). Syntheses of educational productivity research. International Journal of Educational Research, 11(2), 147-252. https://dx.doi.org/10.1016/08830355(87)90035-8

Han, H. B., \& Li, Q. S. (2010). Analysis of TFP in Chinese higher education based on Malmquist index [J]. In Fudan Education Forum 4, 58-62, https://dx.doi.org/10.3969/j.issn.1672-0059.2010.04.011

Johnes, J. (2008). Efficiency and productivity change in the English higher education sector from 1996/97 to 2004/5. The Manchester School, 76(6), 653-674. https://dx.doi.org/10.1111/j.1467-9957.2008.01087.x 
Levin, H. M. (1991). Raising productivity in higher education. The Journal of Higher Education, 62(3), 241262. https://dx.doi.org/10.2307/1982281

Li, Q. (2015). Evaluation on the efficiency of Chinese higher education based on super efficiency DEA Model, Heilongjiang Researches on Higher Education, (9), 153-156. https://dx.doi.org/10.3969/j.issn.10032614.2015.09.043

Luo, Q. Y., Shou, J. M. (2016). operating efficiency evaluation of listed port companies based on factor analysis and SBM super efficiency model. Science Technology and Industry, 3, 92-100. https://dx.doi.org/10.3969/j.issn.1671-1807.2016.03.019

Monk, D. H. (1992). Education productivity research: An update and assessment of its role in education finance reform. Educational Evaluation and Policy Analysis, 14(4), 307-332. https://doi.org/10.2307/1164278

Nazarko, J., \& Šaparauskas, J. (2014). Application of DEA method in efficiency evaluation of public higher education institutions. Technological and Economic Development of Economy, 20(1), 25-44. https://doi.org/10.3846/20294913.2014.837116.

Odden, A., \& Clune, W. (1995). Improving educational productivity and school finance. Educational Researcher, 24(9), 6-22. https://doi.org/10.2307/1177265

Pan, H. S., \& Zhou, Z. G. (2007). Analysis of the total factor productivity of China higher education based on Malmquist index [J]. Journal of Xidian University (Social Science Edition), 6, 003. https://doi.org/10.3969/j.issn.1008-472X.2007.06.002

Sarrico, C. S., Hogan, S. M., Dyson, R. G., \& Athanassopoulos, A. D. (1997). Data envelopment analysis and university selection. Journal of the Operational Research Society,48(12), 1163-1177. https://doi.org/10.1038/sj.jors.2600475

Thanassoulis, E., Kortelainen, M., Johnes, G., \& Johnes, J. (2011). Costs and efficiency of higher education institutions in England: a DEA analysis. Journal of the operational research society, 62(7), 1282-1297. https://doi.org/10.1057/jors.2010.68

Worthington, A. C., \& Lee, B. L. (2008). Efficiency, technology and productivity change in Australian universities, 1998-2003. Economics of education review, 27(3), 285-298. https://doi.org/10.1016/j.econedurev.2006.09.012.

Zhong, W., \& Jiang, W. J. (2017). Efficiency and Productivity Change in the Chinese Higher Education Sector after University Enrollment Expansion. Statistical Research, 1, 91-101, https://doi.org/10.19343/j.cnki.111302/c.2017.01.009. 